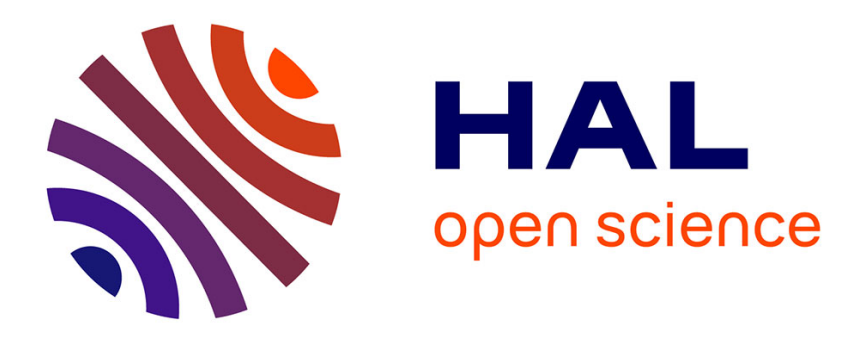

\title{
Charged dislocations and the plastic deformation of II-VI compounds
}

\author{
V. Petrenko, R. Whitworth
}

\section{To cite this version:}

V. Petrenko, R. Whitworth. Charged dislocations and the plastic deformation of II-VI compounds. Journal de Physique Colloques, 1980, 41 (C6), pp.C6-182-C6-185. 10.1051/jphyscol:1980647 . jpa00220085

\section{HAL Id: jpa-00220085 https://hal.science/jpa-00220085}

Submitted on 1 Jan 1980

HAL is a multi-disciplinary open access archive for the deposit and dissemination of scientific research documents, whether they are published or not. The documents may come from teaching and research institutions in France or abroad, or from public or private research centers.
L'archive ouverte pluridisciplinaire HAL, est destinée au dépôt et à la diffusion de documents scientifiques de niveau recherche, publiés ou non, émanant des établissements d'enseignement et de recherche français ou étrangers, des laboratoires publics ou privés. 


\title{
Charged dislocations and the plastic deformation of II-VI compounds
}

\author{
V. F. Petrenko \\ Institute of Solid State Physics of the Academy of Sciences, Chernogolovka, USSR \\ and R. W. Whitworth \\ Department of Physics, University of Birmingham, Birmingham B15 2TT, England
}

\begin{abstract}
Résumé. - Le flux de charges associé à la déformation plastique d'une série de composés II-VI est étudié et à l'obscurité et sous illumination. Il provient du mouvement des dislocations chargées. Il est interprété à l'aide d'un modèle ionique dans lequel il existe des niveaux d'énergie électroniques au cœur de la dislocation. Les résultats permettent d'obtenir des données sur les types de plans de glissement et de dislocations qui sont à l'origine
\end{abstract} de cet effet.

\begin{abstract}
The flow of charge associated with the plastic deformation of a range of II-VI compounds is studied both in darkness and under illumination. It arises from the movement of charged dislocations, and is discussed in terms of an ionic model in which there are electronic energy levels at the dislocation core. The results provide some evidence conceming the types of slip plane and the dislocations involved.
\end{abstract}

1. Introduction. - The tetrahedrally coordinated II-VI compounds like $\mathrm{ZnS}$ are electrically insulating crystals in which according to theory [1] the group II atom carries a positive charge and the group VI atom a negative charge. In this sense they resemble materials like $\mathrm{MgO}$ or even $\mathrm{NaCl}$ which are commonly accepted as ionic, but the tetrahedral coordination is evidence of some covalent character [2] and the smaller band gaps lead to their also being considered along with the more familiar semiconductors.

The properties of dislocations in the II-VI compounds have been studied in many experiments over the past decade, the most detailed being those of Osip'yan, Petrenko and co-workers (e.g. [3-10]). In this paper new results covering a wide range of II-VI compounds will be discussed by treating the materials as ionic crystals in which there are electronic levels within the band gap associated with dislocations and other defects. The results and arguments are described more fully in [11].

2. Ionic model of dislocations. - The structure of cubic $\mathrm{ZnS}$ (sphalerite) is illustrated in figure 1. It consists of alternate (111) layers of $\mathrm{Zn}$ and $\mathrm{S}$ ions stacked in the sequence $\mathrm{AaBbCcAaB} \ldots$, where upper case letters represent $\mathrm{Zn}$ layers and lower case letters $\mathrm{S}$ layers. In plastic deformation slip occurs parallel to these (111) planes. It may in principle occur either between the widely spaced layers like $\mathrm{Cc}$ (known as the shuffle set of slip planes) or between the more closely spaced layers such as aB (the glide set) [12]. The four types of edge dislocation that may be involved are indicated to the right of the diagram and are

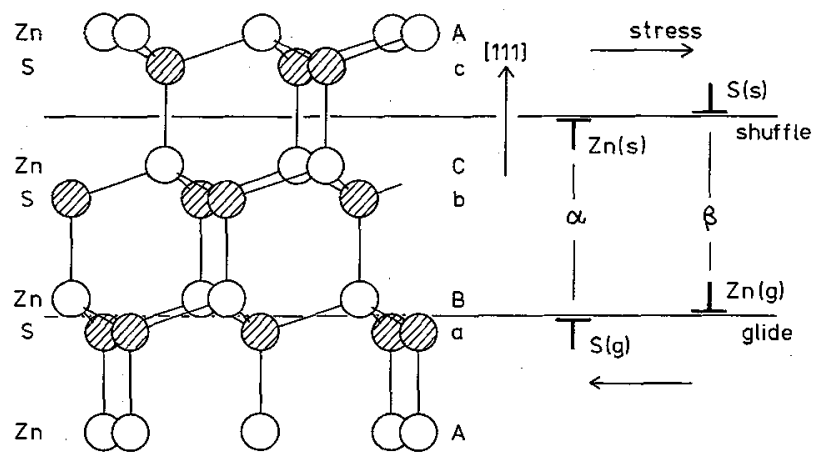

Fig. 1. - The structure of cubic $\mathrm{ZnS}$ (sphalerite) showing possible slip planes of the glide and shuffle sets and the four types of edge dislocation that may be involved. Under the stress shown $\alpha$-dislocations move to the left and $\beta$-dislocations to the right.

denoted by symbols that indicate the ion ( $\mathrm{Zn}$ or $\mathrm{S}$ ) at the end of the extra half-plane and whether they move on planes of the glide or the shuffle set ( $\mathrm{g}$ or s). Dislocations that move to the left under the stress shown will be called $\alpha$-dislocations and may be either $\mathrm{Zn}(\mathrm{s})$ or $\mathrm{S}(\mathrm{g})$; those that move to the right are $\beta$ dislocations $(\mathrm{Zn}(\mathrm{g})$ or $\mathrm{S}(\mathrm{s}))$.

Materials with the hexagonal wurtzite structure consist of (0001) layers stacked AaBbAaB... We will consider only slip parallel to these planes, and the types of dislocations that may be involved are the same as those indicated in the right-hand part of figure 1.

As the core of a dislocation with an edge component consists of a row of ions of the same sign, the disloca- 
tion will be electrically charged and will transport this charge as it glides. Arguments of the kind developed in thinking about other ionic structures $[12,13]$ have been extended to deal with these polar crystals and show that the charges $q$ per lattice spacing along $60^{\circ} \mathrm{Zn}(\mathrm{s})$ - and $\mathrm{Zn}(\mathrm{g})$-dislocations are $+\frac{1}{4} q_{\mathrm{i}}$ and $+\frac{3}{4} q_{\mathrm{i}}$ where $q_{\mathrm{i}}$ is the ionic charge [11]. The charges on the corresponding S-dislocations are equal but of negative sign. In practice these materials are not fully ionic and $q_{\mathrm{i}}$ is often considered to be less than $2 e$. When a partially covalent bond is broken to form a pair of $\mathrm{Zn}$ - and S-dislocations, a given electron must be left either on one ion or the other, and in a dislocation core it does not therefore seem appropriate simply to use the effective value of $q_{\mathrm{i}}$. We propose that when the bond is broken the electron should initially be thought of as being left on the $S$ ion. This gives the dislocations the full ionic charges quoted above, but there will then be donor states at the Sdislocations and acceptor states at the $\mathrm{Zn}$-dislocations. Electrons may be transferred between these states and other states in the crystal, thus modifying and in principle even reversing the dislocation charges.

3. Experiments. - Experiments were performed on monocrystals of $\mathrm{ZnS}, \mathrm{ZnSe}, \mathrm{ZnTe}, \mathrm{CdS}$, CdSe and CdTe grown from the melt and on $\mathrm{ZnO}$ grown from solution in molten $\mathrm{KOH}$. Their structures and nor p-character are listed in table I. Rectangular specimens were deformed in compression in the absolute orientation shown in figure 2 . The dislocations designated $\alpha$ or $\beta$ in figure 1 move in the directions indicated; they produce an electric current between electrodes on the side faces, and this is measured by an electrometer. (At a deformation rate of $10 \mu \mathrm{m} \mathrm{min} .^{-1}$ the current is of order $1 \mathrm{nA}$, larger than effects due to piezoelectricity.) The $\alpha$ - and $\beta$-dislocations are structurally different and are not in general equally mobile. Etching of lightly deformed specimens establishes which type of dislocation is the more mobile, and by assuming the deformation to be entirely by edge dislocations it is possible to estimate a lower limit to the charge $q$ carried by these dislocations. Results obtained in darkness at room temperature are summarised in table I.

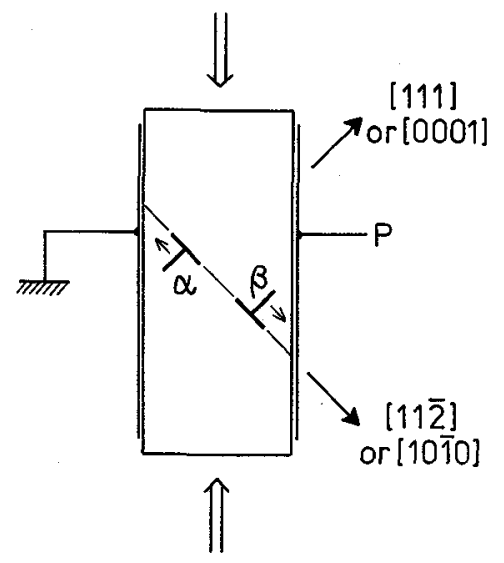

Fig. 2. - A specimen oriented for deformation in compression with electrodes on its faces. Typical dimensions are $6 \mathrm{~mm}$ high, $1.5 \mathrm{~mm}$ wide and $4 \mathrm{~mm}$ perpendicular to the diagram.

$\mathrm{ZnS}$ is a special case in that although it has the sphalerite structure there are a large number of stacking faults and micro-twins parallel to a single set of (111) planes; this gives it pseudo-hexagonal symmetry with the polarity of the sequence of $\mathrm{Zn}$ and $\mathrm{S}$ layers along the hexagonal axis being maintained throughout the crystal. It is a known property of $\mathrm{ZnS}$, confirmed by us for the specimens used, that plastic deformation converts the pseudo-hexagonal crystals into a more cubic structure [14-16]. This must involve much if not all of the slip occurring by the movement of partial dislocations on planes of the glide set [17]. The magnitude of $q$ for $\mathrm{ZnS}$ in table I is calculated for partial dislocations, but for the other materials the value given is for perfect dislocations (or pairs of partials taken together). It has not so far been possible to find a satisfactory etchant for $\mathrm{ZnS}$, and in this case there is therefore no direct evidence of the type $(\alpha$ or $\beta$ ) of the mobile dislocations or of the sign of their charge.

On illumination with light in a broad band of frequencies (with a maximum effect at about 0.9 of the band gap $[4,9])$ all the crystals exhibited a photoplastic effect in which both the flow stress and the magnitude of the dislocation charge were increased. Measurements of the resolved shear stress $\tau$ and

Table I.

$\begin{array}{clc}\text { Material } & \text { Structure } & \text { Type } \\ - & - & - \\ \mathrm{ZnO} & \text { wurtz. } & \mathrm{n} \\ \mathrm{ZnS} & \text { sphal. }\left({ }^{1}\right) & \mathrm{n} \\ \mathrm{ZnSe} & \text { sphal. } & \mathrm{n} \\ \mathrm{ZnTe} & \text { sphal. } & \mathrm{p} \\ \mathrm{CdS} & \text { wurtz. } & \mathrm{n} \\ \mathrm{CdSe} & \text { wurtz. } & \mathrm{n} \\ \mathrm{CdTe} & \text { sphal. } & \mathrm{n}\end{array}$

Mobile
dislocations
-
$\beta$
$\alpha\left({ }^{2}\right)$
$\alpha$
$\alpha$
$\beta$
$\beta$
$\alpha$

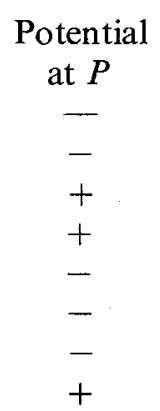

$$
\begin{gathered}
\begin{array}{c}
\text { Charge } q \\
(e / b)
\end{array} \\
-\overline{-} \\
-\left(^{2}\right) 0.54 \\
-0.50 \\
+0.42 \\
-0.36 \\
-0.17
\end{gathered}
$$

$\left({ }^{3}\right)$ For partial dislocations.

(1) Pseudo-hexagonal due to stacking faults.

${ }^{2}$ Inferred, see text. 
dislocation charge $q$ for a variety of crystals both in darkness and under different levels of illumination are shown in figure 3.

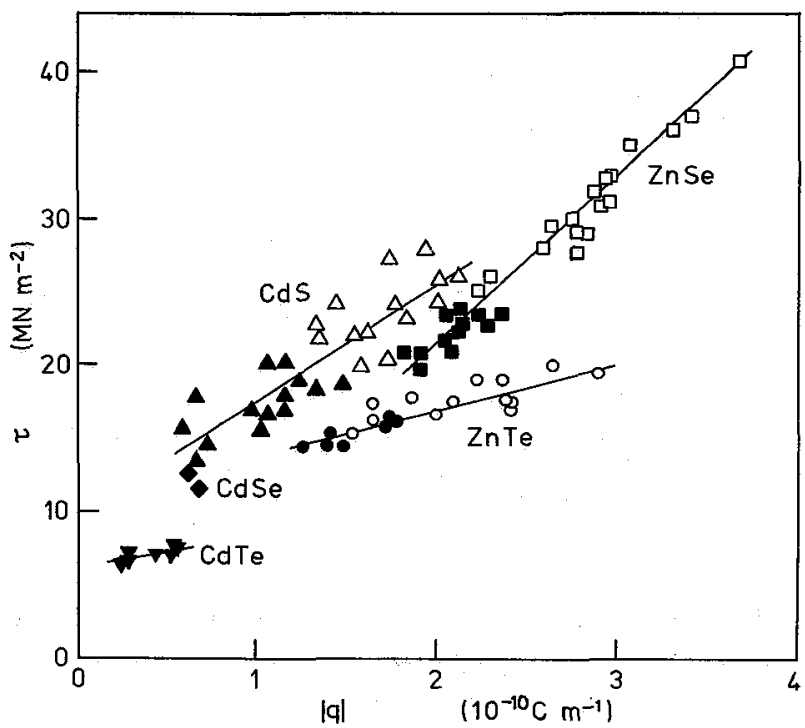

Fig. 3. - Resolved shear stress $\tau$ and magnitude of dislocation charge $|q|$ observed in plastic deformation of II-VI compounds at room temperature in darkness (solid points) and under various levels of illumination (open points).

4. Discussion. - If the materials were fully ionic so that the $\mathrm{Zn}$-dislocations were known to carry a positive charge and $\mathrm{S}$-dislocations a negative charge, the sign of the potential at $P$ given in table $I$ would depend on whether the dislocations move on planes of the glide or the shuffle set [18]. Table 1 shows, however, that the sign of the observed dislocation charge seems to depend primarily on whether the crystal is $n$ - or p-type, and earlier experiments on $n$ type CdS [7] have shown that both the $\alpha$ - and $\beta$ dislocations have a negative charge. These observations, together with the fact that illumination changes the dislocation charge, indicate that this charge is not a purely ionic property of the dislocations, but must arise from an equilibrium of electrons between the dislocations and other levels in the crystal. This equilibrium cannot be a simple thermal equilibrium of the kind originally discussed by Read [19], and Kirichenko, Petrenko and Uimin [8] have developed a model for the dynamic equilibrium of electrons between moving dislocations and fixed point defects or impurities. Their model is successful in accounting for detailed observations on $\mathrm{ZnSe}$ [8] and some general features across the range of materials described here [11]. In this model as revised in [11] the dislocation charge consists of the ionic component $\left( \pm \frac{1}{4} q_{i}\right.$ or $\pm \frac{3}{4} q_{\mathrm{i}}$ ) already discussed plus an additional charge due to bound electrons or holes. The important parameter determining the equilibrium is the total charge irrespective of how it is made up.

In no case do the experiments provide a unique identification of the types of dislocations involved, but we have a clue in the case of $\mathrm{ZnS}$ which, as explained, must deform primarily on planes of the glide set. If we assume that the dislocations are negatively charged as in all other n-type crystals, the observed dislocation current indicates that the dislocations are of $\alpha$-type and therefore $\mathrm{S}(\mathrm{g})$. If this is so then for all the materials studied the mobile dislocations are the $\alpha$-dislocations in the sphalerite structures and the $\beta$-dislocations in the wurtzite structures. By analogy with $\mathrm{ZnS}$ it seems likely that the mobile dislocations in $\mathrm{ZnSe}$ are negatively charged $\mathrm{Se}(\mathrm{g})$, but beyond this point speculation becomes difficult. We cannot tell for example whether the mobile $\beta$-dislocations in $\mathrm{CdS}$ are ionically negative $\mathrm{S}(\mathrm{s})$ or are $\mathrm{Cd}(\mathrm{g})$ whose charge has been reversed by the addition of about two electrons per ion along the core. In either case the situation is very different from that in $\mathrm{ZnS}$ or ZnSe.

Figure 3 shows a correlation between $\tau$ and $q$ in different materials, in different samples of a given material and under differing levels of illumination. (The special case of $\mathrm{ZnS}$ is discussed in [11].) Coupled with more detailed experiments on $\mathrm{ZnSe}$ [9], these results suggest that the physical process limiting the mobility of a dislocation is related to its charge. A possible model is discussed by Osip'yan and $\mathrm{Pe}$ trenko [9].

We have shown that considerable progress can be made in understanding dislocations in the II-VI compounds using an ionic model, but it is essential to take into account the presence of electronic energy levels localised at dislocations and having energies within the band gap. The idea of electronic levels in the more usual ionic crystals is a familiar one, but the possibility of there being such levels at dislocations has received little attention. There is no reason why such states must exist in all materials, but the possibility needs to be borne in mind.

\section{DISCUSSION}

\section{Question. - F. GranzER.}

In your model dislocations do not contain jogs. Would the presence of jogs cause a change from the shuffle to the glide configuration in the same dislocation?

\section{Reply. - R. W. WHITWORTH.}

The structures of dislocations on planes of the glide and shuffle set are very different and we think it would be an unlikely coincidence if these dislocations had equal mobility. We therefore assume that only 
one type of slip plane operates during deformation, and that mobile jogs go from one kind of slip plane to an adjacent plane of the same set.

\section{Question. - T. E. Mirchell.}

Would you care to speculate on the nature of the electrostatic barrier to dislocation motion. Is this a modification to the Peierls stress or an interaction with charged impurities?

\section{Reply. - R. W. WhiTwORTH.}

Our evidence is that the stress to move a dislocation is related to the charge carried by the moving dislocation. We suspect that it does not depend much on the impurities except in so far as they determine the dislocation charge. This suggests a Peierls type of barrier and Osip'yan and Petrenko [9] have proposed a model based on the interaction of the dislocation charge with the ionic charges in the lattice. We realise that this cannot be correct in detail but it gives a stress of the right order of magnitude.

\section{Question. - A. ATKInson.}

Does the electronic conductivity influence the measurements of charge transfer.

\section{Reply. - R. W. WhITWORTH.}

Our results are obtained on crystals which are effectively insulators. In samples or under conditions of illumination where the electronic conductivity is too high we are unable to measure the dislocation currents. This of course limits the technique to suitably insulating materials.

\section{Question. - J. Castaing.}

How far can environmental effects due to electrodes influence the observed effects? It is known that e.g. in $\mathrm{NaCl}$ moisture seems to induce (111) slip plane instead of (100) (compression axis $\langle 111\rangle$ ).

\section{Reply. - R. W. WhITWORTH.}

We have used various kinds of electrodes without producing significant changes in the effect. However it is important whether the electrodes are isolated or connected together. In the former case a space charge builds up producing an electric field opposing further dislocation movement and this increases the flow stress, but this does not occur if the electrodes are shorted. Moisture produces a conducting layer on the surface of $\mathrm{NaCl}$, and I don't know whether this might produce any corresponding effect.

\section{Question. - J. JANSZKY.}

In the literature there were some hints about the possibility to use charged dislocations of polar semiconductors as electronic elements. How do you estimate such possibility now ?

\section{Reply. - R. W. WhITWORTH.}

No comment.

\section{References}

[1] Chelikowsky, J. R. and Cohen, M. L., Phys. Rev. B 14 (1976) 556.

[2] Phillips, J. C., Treatise on Solid State Chemistry, ed. N. B. Hannay (Plenum Press, New York) 1973, Vol. 1, chap. 1.

[3] Osip'yan, Yu. A. and Savchenxo, I. B., Pis'ma Zh. Eksp. Teor. Fiz. 7 (1968) 130; JETP Lett. 7 (1968) 100.

[4] Osip'yan, Yu. A. and Petrenko, V. F., Zh. Eksp. Teor. Fiz. 63 (1972) 1735 ; Sov. Phys. JETP 36 (1973) 916.

[5] Osip'yan, Yu. A. and Petrenko, V. F., Zh. Eksp. Teor. Fiz. 69 (1975) 1362 ; Sov. Phys. JETP 42 (1976) 695.

[6] Osip'Yan, Yu. A. and Petrenko, V. F., Dokl. Akad. Nauk. SSSR 226 (1976) 803; Sov. Phys. Dokl. 21 (1976) 87.

[7] Zaretskĭ, A. V., Osip'yan, Yu. A., Petrenko, V. F. and Strukova, G. K., Fiz. Tverd. Tela 19 (1977) 418; Sov. Phys. Sol. St. 19 (1977) 240.

[8] Kirichenko, L. G., Petrenko, V. F. and Uĩmin, G. V., $Z h$. Eksp. Teor. Fiz. 74 (1978) 742; Sov. Phys. JETP 47 (1978) 389.

[9] Osip'yan, Yu. A. and Petrenko, V. F., Zh. Eksp. Teor. Fiz. 75 (1978) 296; Sov. Phys. JETP 48 (1978) 147.
[10] Osip'yan, Yu. A. and Petrenko, V. F., J. Physique Colloq. 40 (1979) C6-161.

[11] Petrenko, V. F. and Whitworth, R. W., Phil. Mag. A 41 (1980) 681.

[12] HIRTH, J. P. and Lothe, J., Theory of Dislocations (McGrawHill, New York) 1968.

[13] Whitworth, R. W., Adv. Phys. 24 (1975) 203.

[14] Abdikamalov, B. A., Kulakov, M. P., Shekhrman, V. Sh. and Shmurak, S. Z., Fiz. Tverd. Tela 17 (1975) 3463; Sov. Phys. Sol. St. 17 (1975) 2268.

[15] Shekhtman, V. Sh., Shmyt'ko, I. M., Aristov, V. V. and Abdikamalov, B. A., Fiz Tuerd. Tela 18 (1976) 1358; Sov. Phys. Sol. St. 18 (1976) 781.

[16] Abdikamalov, B. A., Bredikhin, S. I., Kulakov, M. P., ShekHTMan, V. Sh. and Shmurak, S. Z., Fiz. Tverd. Tela 18 (1976) 2468; Sov. Phys. Sol. St. 18 (1976) 1442.

[17] D'Aragona, F. S., Delavignette, P. and Amelinckx, S., Phys. Status Solidi 14 (1966) K115.

[18] Speake, C. C., SMith, P. J., LOMER, T. R. and Whitworth, R. W., Phil. Mag. A 38 (1978) 603.

[19] Read, W. T., Phil. Mag. 45 (1954) 775. 